\title{
Survey and identification of palm tree species at some ornamental plant stores and nurseries in Ho Chi Minh City and using palm trees in garden design
}

\author{
Chi. T. K. Tran, Quan. V. Nguyen, \& Tien. T. M. Duong*
}

Faculty of Environment and Natural Resources, Nong Lam University, Ho Chi Minh City, Vietnam

ARTICLE INFO
Research Paper
Received: April 08, 2021
Revised: June 30, 2021
Accepted: July 05, 2021
Keywords
Arecaceae
Garden design
Ho Chi Minh City
Ornamental plants
Palm
*Corresponding author
Duong Thi My Tien
Email: duongmytien@hcmuaf.edu.vn

\begin{abstract}
The study was conducted from June to September 2020 in Ho Chi Minh City. This research aimed to identify the palm species and incorporate them into the garden design. To investigate the species, 85 ornamental plant stores and nurseries were surveyed in Go Vap district, District 7 and at Highway 22. Then, morphological comparison method was used for plant species classification. According to the analyses, this region had 25 species belonging to 22 genera in the Arecaceae family. Twenty two of the 25 species surveyed were imported and 03 being native to the area. The majority (68\%) was solitary-stemmed palms, with the remaining 08 species having clustered trunks $(32 \%)$. To incorporate palm trees into the garden design, Sketch-up, Lumion, and Photoshop software were used.
\end{abstract}

Cited as: Tran, C. T. K., Nguyen, Q. V., \& Duong, T. T. M. (2021). Survey and identification of palm tree species at some ornamental plant stores and nurseries in Ho Chi Minh City and using palm trees in garden design. The Journal of Agriculture and Development 20(4), 43-52. 


\title{
Khảo sát, định danh cây họ cau dừa tại các vựa kiểng ở Thành phố Hồ Chí Minh và ứng dụng trong thiết kế sân vườn
}

\author{
Trần Thị Kim Chi, Nguyễn Văn Quân \& Dương Thị Mỹ Tiên* \\ Khoa Môi Trường và Tài Nguyên, Trường Đại Học Nông Lâm TP.HCM, TP. Hồ Chí Minh
}

\section{THÔNG TIN BÀI BÁO}

Bài báo khoa học

Ngày nhận: 08/04/2021

Ngày chỉnh sửa: 30/06/2021

Ngày chấp nhận: 05/07/2021

Từ khóa

Cây cảnh

Cây cau dừa

Họ cau dừa

Thiết kế sân vườn

TP.HCM

*Tác giả liên hệ

Dương Thị Mỹ Tiên

Email: duongmytien@hcmuaf.edu.vn

\section{TÓM TẮT}

Nghiên cứu được tiến hành từ tháng 06 đến tháng 09 năm 2020 tại các vựa kiểng ở Thành phố Hồ Chí Minh. Nghiên cứu được thực hiện bằng các phương pháp như điều tra, chụp ảnh, so sánh hình thái, tổng hợp số liệu, thiết kế. Nghiên cứu đã định danh, thống kê và phân tích được cây họ Cau dừa tại các vựa kiểng ở Thành phố Hồ Chí Minh và ứng dụng phối kết vào trong thiết kế sân vườn. Kết quả nghiên cứu định danh được 25 loài thuộc 22 chi của họ Cau dừa (Arecaceae). Trong 25 loài điều tra có 22 loài có nguồn gốc nhập nội, 3 loài có nguồn gốc bản địa. Đa số là cây họ Cau dừa có thân mọc đơn độc $(68 \%)$ còn lại là 8 loài có thân mọc cụm thành dạng bụi $(32 \%)$. Sử dụng phần mềm Sketch - up, Lumion, Photoshop thiết kế ứng dụng cây họ Cau dừa vào thiết kế cảnh quan.

\section{1. Đặt Vấn Đề}

Không gian xanh đô thị có thể cung cấp một loạt các dịch vụ hệ sinh thái, bao gồm bảo tồn đa dạng sinh học, du lịch văn hóa, hấp thụ carbon,... (Bennett \& ctv., 2009; Hansen \& Pauleit, 2014). Thảm thực vật thường được coi là đóng một vai trò quan trọng trong việc cải thiện chất lượng không khí trong công viên đô thị (Xing \& Brimblecombe, 2019). Giá trị phẩm chất của cây xanh đô thị bị ảnh hưởng bởi tình trạng sức khỏe và giá trị thẩm mỹ, nhưng cả hai tiêu chí trên đều có khuynh hướng chủ quan của người đánh giá (Watson, 2002).

Trên toàn thế giới, nhiều loài cây khác nhau đã được tôn thờ và ca ngợi vì chúng có ý nghĩa văn hóa ở nhiều quốc gia (Zhang \& ctv., 2020). Ở Hoa Kỳ, miền Nam California và những nơi khác cây họ Cau dừa mang ý nghĩa văn hóa, nó tượng trưng cho sự thư thái và quyến rũ (Farmer, 2013). Trong bối cảnh đô thị ngày nay, cây họ
Cau dừa chủ yếu được trồng vì giá trị thẩm mỹ và văn hóa (Farmer, 2013), vì qua chức năng và tuổi thọ, chúng ít cần được bảo dưỡng hơn cây rụng lá và cây hạt trần (Peper \& ctv., 2010).

Cây họ Cau dừa từ lâu được xem là một loài độc nhất và dễ nhận biết của thành phần rừng đô thị. Đây là loài được đánh giá cao về hình dáng và tính hữu dụng như quả ăn được, cây họ Cau dừa được chọn làm rừng trồng trong khu vườn Ai Cập cổ đại (Hauer \& ctv., 2017). Mặc dù cây họ Cau dừa có nhiều điểm chung về mặt sinh học với cây thân thảo hơn các loài cây lá kim và cây thân gỗ lá rộng, nhưng chúng thường được quản lý như cây gỗ trong nghề làm vườn và lâm nghiệp đô thị (Ali \& Burkhart, 2017).

Với những không gian bị hạn chế đối với cây gỗ lớn, cây họ Cau dừa có thể tồn tại và sẽ không gây hư hỏng cơ sở hạ tầng xung quanh. Trồng những cây họ Cau dừa trưởng thành, có thể tác động trực quan ngay lập tức đến cảnh quan đô thị (Hodel \& ctv., 2005). Chi phí trồng cây họ 
Cau dừa trưởng thành có thể cao, tuy nhiên chủ đầu tư, nhà thầu cảnh quan và các bên liên quan khác có thể có ngay lợi ích về sức khỏe và đảm bảo chúng tồn tại lâu dài (Koeser \& ctv., 2014; Roman \& ctv., 2016; Elmes \& ctv., 2018).

Họ Cau dừa (Arecaceae hay Palmae) là họ thực vật nhiệt đới có khoảng 250 chi gồm khoảng 2.500 loài, phân bố chủ yếu ở các nước nhiệt đới Châu Á và Châu Mỹ La tinh (Dransfield \& ctv., 2008) là một họ trong thực vật có hoa, thuộc về lớp thực vật một lá mầm và nằm trong bộ Cau (Arecales). Họ Cau dừa gồm những cây thân cột không phân nhánh hoặc dây leo. Sự phân nhánh của thân họ Cau dừa là rất hiếm, xảy ra một cách tự nhiên và dễ thấy chỉ một số loài, chẳng hạn như cây cọ Doum, Gingerbread (Hyphaene spp.) (Dransfield \& ctv., 2008). Phân nhánh trên không đôi khi xảy ra ở các loài khác, nó là một hiện tượng bất thường được cho là kết quả của vết thương hoặc tổn thương mô phân sinh đỉnh hoặc rối loạn dinh dưỡng (Broschat, 2007). Ở Việt Nam, các loài thực vật trong họ Cau dừa rất thân thuộc, gắn liền với đời sống của người dân Việt Nam, từ câu chuyện "trầu, cau và vôi" ở Bắc Bộ tới những vườn dừa Nam Bộ, cùng với các vật dụng thân thuộc được làm từ các loài song mây, lá nón (Nguyen, 2017). Rất nhiều loài thực vật họ Cau dừa được sử dụng hoặc có tiềm năng làm cây cảnh trên toàn quốc (Nguyen, 2017). Nghiên cứu "Khảo sát, định danh cây họ Cau dừa tại các vựa kiểng ở quận Gò Vấp, quận 7, quốc lộ 22 (huyện Hóc Môn) Thành phố Hồ Chí Minh và ứng dụng trong thiết kế cảnh quan" nhằm cung cấp và cập nhật những thông tin về cây họ Cau dừa từ những nghiên cứu trước, phúc tra và làm cơ sở cho những nghiên cứu về cây họ Cau dừa sau này. Đồng thời, bổ sung thêm nghiên cứu về ứng dụng phối kết cây cau dừa trong cảnh quan.

\section{Vật Liệu Và Phương Pháp Nghiên Cứu}

\subsection{Phương pháp ngoại nghiệp}

Phương pháp điều tra và chụp ảnh: Chụp ảnh, phỏng vấn các chủ vựa kiểng về nguồn gốc, tên thương mại và một số đặc điểm của cây họ Cau dừa. Chụp ảnh tổng quát đến chi tiết các bộ phận như: thân, lá, cuống lá, bẹ lá, hoa, quả để phục vụ cho việc định danh các cây họ Cau dừa. Chụp và viết lại số hiệu ảnh trong phiếu điều tra để mã hóa ảnh chụp thuận tiện trong việc nhận dạng và dịnh danh.

\subsection{Phương pháp nội nghiệp}

Phương pháp định loại: Đối với các loài thông thường đã biết tên, có thể định danh loài ngay tại hiện trường bằng phương pháp quan sát và phân tích hình thái, sau đó so sánh mẫu với các mẫu chuẩn của các loài đó ở các bảo tàng trong và ngoài ngước. Đối với các loài lạ (chưa xác định), tiến hành phân tích mẫu, so sánh về mặt hình thái với các loài tương tự (Nguyen, 2017). Dựa trên tài liệu nghiên cứu, các mô tả của phiếu điều tra, các hình ảnh chụp được, tiến hành so sánh hình thái và cấu tạo bên ngoài của thực vật, so sánh các đặc điểm hình thái của cơ quan sinh dưỡng và cơ quan sinh sản giữa các cá thể với nhau. Dựa vào sự giống nhau và khác nhau đó của các bộ phận để sắp xếp vào các bậc phân loại. Khi phân loại cần tránh sự nhầm lẫn các đặc điểm thể hiện mối quan hệ thân cận. Khi so sánh thì cần so sánh các cơ quan tương ứng (homologues) chứ không nên so sánh giữa các cơ quan tương tự (analogues) với nhau. Các loài cây họ Cau dừa mới được điều tra, thu thập sẽ được đem so sánh hình thái với các loài cây trong tác phẩm các tài liệu trước.

Phương pháp tổng hợp số liệu: Dữ liệu sau khi thu thập được tổng hợp trên phần mềm Microsoft Excel và Microsoft Word.

Phương pháp thiết kế: Thiết kế bản vẽ phối cảnh có sử dụng các loài thực vật họ Cau dừa bằng phần mềm Sketch - up, Lumion và Photoshop.

\section{Kết Quả và Thảo Luận}

\subsection{Thành phần loài đã điều tra}

Dựa trên phương pháp chọn mẫu phi ngẫu nhiên (chọn mẫu theo chủ đích kết hợp chọn mẫu phát triển mầm) để khoanh vùng điều tra. Nghiên cứu đã điều tra 85 vựa kiểng trên địa bàn 3 quận, huyện tại Thành phố Hồ Chí Minh, định danh và thống kê được 25 loài thuộc 22 chi.

Các vựa kiểng lớn tập trung trên các tuyến đường Phan Huy Ích, Nguyễn Oanh, Dương Quảng Hàm và các tuyến đường lân cận. Đa số là những vựa kiểng hỗn hợp chuyên kinh doanh cây lá màu, cây nội thất. Nhìn chung, quận Gò Vấp là nơi trung chuyển cây đại mộc nói chung và những cây họ Cau dừa có quy cách lớn nói riêng, tại vườn đa số chỉ là những cây có quy cách nhỏ. Tại các tuyến đường Nguyễn Văn Linh, Nguyễn Hữu Thọ của quận 7 đã điều tra được 11 


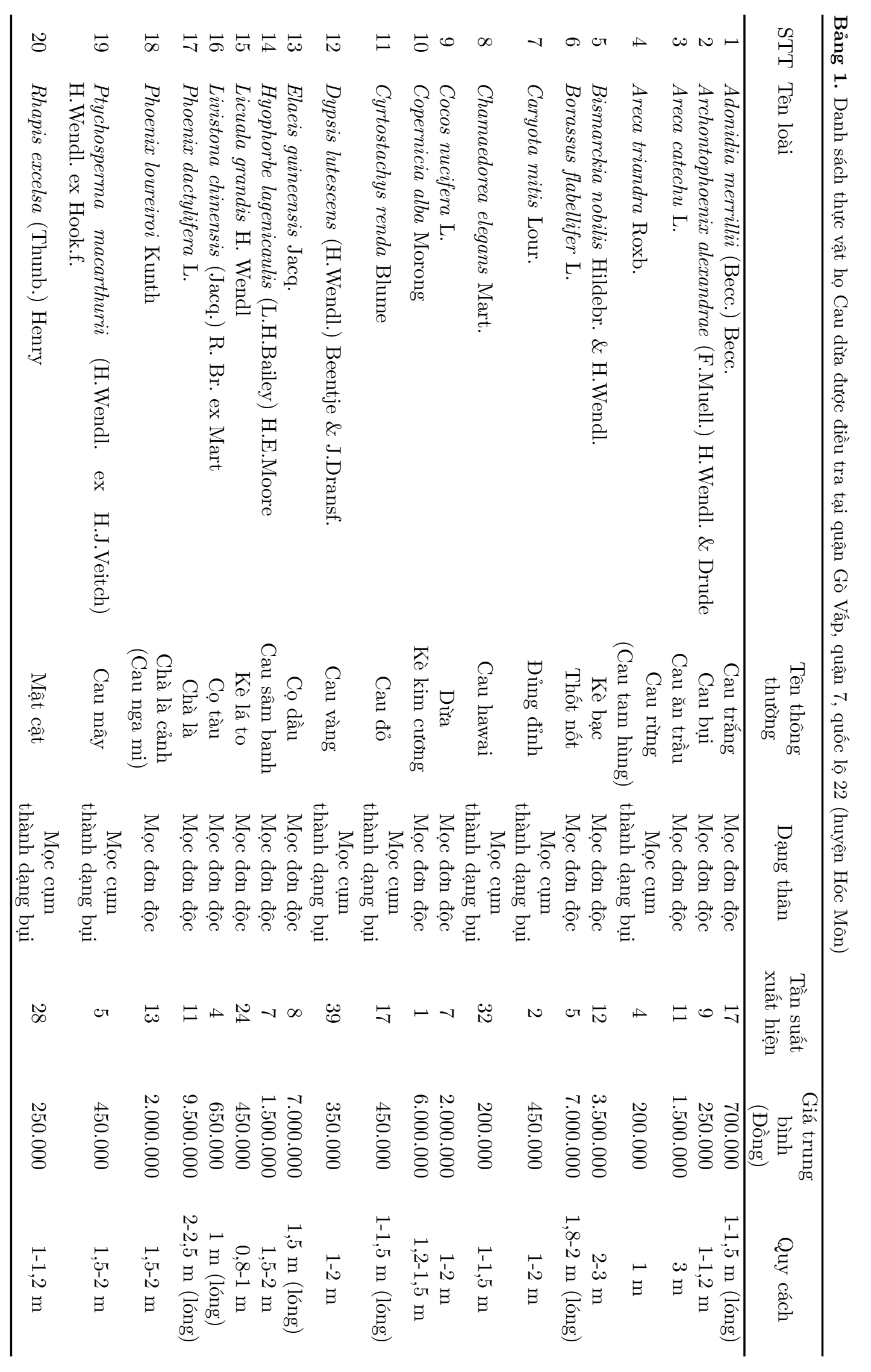


vựa kiểng hỗn hợp đa số là cây công trình. Tại huyện Hóc Môn tập trung điều tra được 6 vựa trên tuyến quốc lộ 22. Có 4 vựa là kinh doanh chuyên về cây họ Cau dừa với các loài như: Kè mỹ, Thốt nốt, Chà là, Cau vua.

Qua kết quả thống kê ở Bảng 1 cho thấy, có 25 loài thuộc 22 chi, các chi có hai loài gồm: Areca, Phoenix, Rhapis còn lại là các chi có một loài: Livistona, Adonidia, Archontophoenix, Bismarckia, Borassus, Caryota, Chamaedorea, Cocos, Copernicia, Cyrtostachys, Dypsis, Elaeis, Hyophorbe, Licuala, Ptychosperma, Roystonea, Saribus, Washingtonia, Wodyetia. Trong đó, chi có thân mọc đơn độc là 16 chi chiếm $73 \%$, chi có thân mọc cựm thành dạng bụi là 6 chi chiếm $27 \%$.

Trong 25 loài điều tra được chỉ có 3 loài mang nguồn gốc bản địa như: Đủng đỉnh (Caryota mitis Lour.) (Duong, 2015), Cau rừng (Areca triandra Roxb.), Chà là cảnh (Phoenix loureiroi Kunth) (Pham, 2003); 22 loài còn lại là cây nhập nội (Pham, 2003; Duong, 2015). Đa số cây họ Cau dừa đều được nhập nội nhưng có một số cây đã được nhập từ rất lâu và đã quen thuộc với người Việt Nam như: Dừa (Cocos nucifera L.), Cọ dầu (Elaeis guineensis Jacq.) có nguồn gốc từ Châu Phi, Cau vua (Roystonea regia O.F. Cook) có nguồn gốc Cuba, Cau đỏ (Cyrtostachys renda Blume) có nguồn gốc Indonesia, Cau vàng (Dypsis lutescens (H.Wendl.) Beentje \& J.Dransf.) có nguồn gốc từ đảo Mauritius (Pham, 2003).

Theo Bảng 1 hầu hết cây họ Cau dừa ở Thành phố Hồ Chí Minh là cây có thân mọc đơn độc $(17 / 25)$ chiếm (68\%). Quận Gò Vấp điều tra được 22/25 loài, số loài Cau dừa có thân mọc đơn độc là $15 / 22$ loài $(68,18 \%)$, quận 7 điều tra được 23 loài, số loài Cau dừa thân mọc đơn độc là 16/23 loài $(69,6 \%)$ và quốc lộ 22 điều tra được 14 loài có 11/14 loài có thân mọc đơn độc (79\%). Lá cây họ Cau dừa có hai dạng chính: lá kép lông chim (18 loài) và lá xẻ chân vịt (7 loài). Vị trí cụm hoa có 3 kiểu: giữa tán lá, ở nách lá và dưới tán lá, trong đó kiểu cụm hoa mọc giữa tán và dưới tán chiếm đa số (23 loài).

Trong tổng số 25 loài, cây có tần số xuất hiện cao tập trung tại quận Gò Vấp với những loài có tần số xuất hiện cao nhất là: Cau vàng (Dypsis lutescens (H.Wendl.) Beentje \& J.Dransf.), Cau hawai (Chamaedorea elegans Mart.), Mật cật (Rhapis excelsa (Thunb.) Henry) và Kè lá to (Licuala grandis $\mathrm{H}$. Wendl). Đa phần những cây có tần số xuất hiện cao là cây có thân mọc cụm 


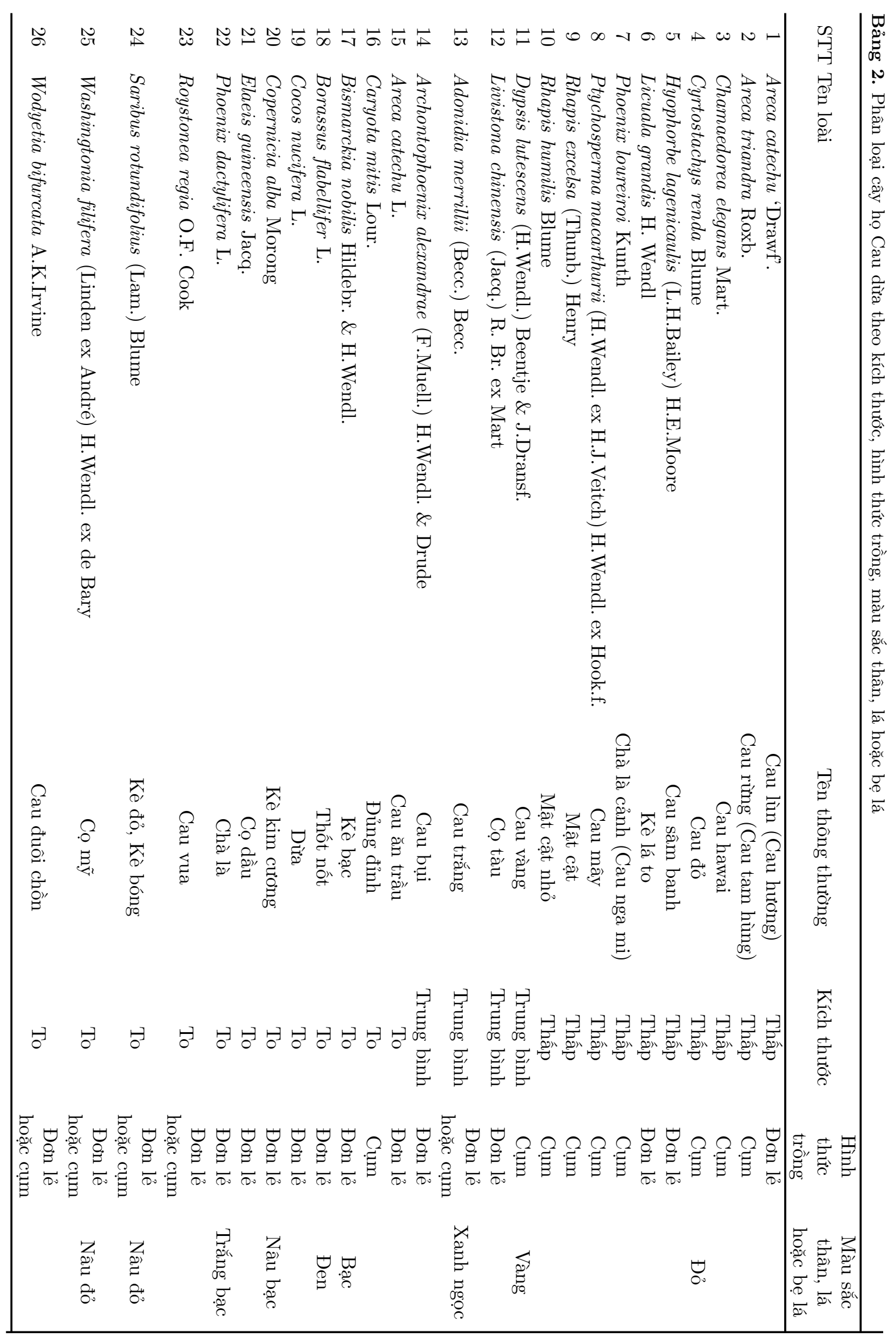


thành dạng bụi được trồng chủ yếu trong chậu trang trí nội thất. Cây có tần số xuất hiện cao nhất là Cau vàng (39 lần), cây có tần số xuất hiện thấp nhất là Kè kim cương (Copernicia alba Morong) (1 lần). Giá bán buôn của cây họ Cau dừa là tùy thuộc quy cách nhập cây, quy cách khác nhau cho mức giá khác nhau. Sự cạnh tranh về giá bán buôn giữa các vựa kiểng cũng làm giá cây họ Cau dừa không cố định.

Qua thống kê tổng số loài cây họ Cau dừa có mặt tại từng vựa kiểng điều tra, thu được kết quả sau: quận Gò Vâp có các vựa kiểng kinh doanh nhiều loài cây họ Cau dừa như: "Chị Đẹp" (12 loài), "Sáu Mơ" (11 loài), "Anh Tưng" (10 loài), "Vườn cây An Lộc" (9 loài). Các vựa kiểng có số loài cây họ Cau dừa đa dạng tại quận 7 là: "Phương Nam" (8 loài), "Bảo Châu" (8 loài), "Nguyễn Châu Garden" (7 loài) và tại quốc lộ 22 (huyện Hóc Môn) có các vựa như: "Chú Hảo" (8 loài), "Anh Long" (7 loài). Đây là những vựa kiểng chuyên kinh doanh cây họ Cau dừa và cây công trình.

Với kết quả điều tra này, nghiên cứu đã bổ sung so với kết quả nghiên cứu thực vật Việt Nam của Pham (2003) thêm 7 loài đó là: Cau bụi ( $A r$ chontophoenixalexandrae (F.Muell.) H.Wendl. \& Drude), Kè bạc (Bismarckia nobilis Hildebr. \& H.Wendl.), Kè kim cương (Copernicia alba Morong), Cau sâm banh (Hyophorbe lagenicaulis (L.H.Bailey) H.E.Moore, Kè đỏ (Saribus rotundifolius (Lam.) Blume), Cau đuôi chồn (Wodyetia bifurcata A.K.Irvine) và Cau mây (Ptychosperma macarthurii (H.Wendl. ex H.J.Veitch) H.Wendl. ex Hook.f.). Trong đó, $7 / 7$ loài điều tra đều là cây nhập nội (Pham, 2003; Duong, 2015).

Kết quả nghiên cứu so với Tran (1998) điều tra không thấy những cây: Cau tua (Dypsis pinnatifrons Mart.), Chà là miên (Phoenix hanceana Naud.), Cọ quạt (Thrinax parviflora Swarts), Dừa xụ (Attalea macrocarpa Linden.), Kè ân (Licuala peltata Roxb), Mật cật gai (Licuala spinosa Wurmb), Lá buông (Corypha lecomtei Becc.) và Lá buông cao (Corypha elata Roxb.) vì theo Tran (1998) và Pham (2003) thì đây là những cây mọc hoang dại trong rừng và có ứng dụng trong sản xuất đồ thủ công mỹ nghệ như Lá buông (Corypha lecomtei Becc.); nhưng bổ sung được các loài cây như: Cọ tàu (Livistona chinensis (Jacq.) R. Br. ex Mart), Kè kim cương (Copernicia alba Morong) và Cau đuôi chồn (Wodyetia bifurcata A.K.Irvine).

Ngày nay xu hướng nhập nội các loài trong họ
Cau dừa tăng cao do thị hiếu trồng cây cảnh. Theo Duong (2015), đa số cây họ Cau dừa có dạng thân cột được dùng làm cảnh $(92,9 \%)$ như Cau trắng (Adonidia merrillii (Becc.) Becc.), Chà là (Phoenix dactylifera L.), Cau đuôi chồn (Wodyetia bifurcata A.K.Irvine), Cau vua (Roystonea regia O.F. Cook), Cau vàng (Dypsis lutescens (H.Wendl.) Beentje \& J.Dransf.). Kết quả nghiên cứu thống kê tần số xuất hiện những loài kể trên cũng cho thấy đây là những loài cây công trình phổ biến bán nhiều ở các vựa kiểng được điều tra do phù hợp với xu hướng sở thích của người dân đô thị, các công trình khu dân cư đô thị, các công ty, nhà thiết kế cảnh quan.

So với Nguyen (2009) đã điều tra bổ sung thêm được 3 loài: Mật cật nhỏ (Rhapis humilis Blume), Kè kim cương (Copernicia alba Morong), Cau bụi (Archontophoenixalexandrae (F.Muell.) H.Wendl. \& Drude). So với RoDa (2011) đã điều tra được 30 loài thực vật họ Cau dừa hiện được trồng sưu tập tại Thảo Cầm Viên Sài Gòn, kết quả nghiên cứu này không thấy những loài: Cau phụng (Chrysalidocarpus madagascariensis Wendl.), Đủng đỉnh lá lớn (Caryota mitis), Cau tam giác (Dypsis decaryi) và Lá buông (Corypha lecomtei Becc.), nhưng nghiên cứu đã bổ sung thêm 3 loài: Cọ tàu (Livistona chinensis (Jacq.) R. Br. ex Mart), Kè kim cương (Copernicia alba Morong), và Cau bụi ( $A r$ chontophoenix alexandrae (F.Muell.) H.Wendl. \& Drude). So với Duong (2015) điều tra ở Tp. Huế, các loài thực vật họ Cau dừa điều tra này không tìm thấy 2 loài dạng thân leo thuộc chi Calamus là: Mây tắt (Calamus faberi Becc.), Mây thủ công (Calamus salicifolius Becc.). Vì theo Pham (2003), 2 loài này có nguồn gốc bản địa, mọc hoang dại ở rừng thưa, bình nguyên, duyên hải, vùng Thừa Thiên Huế. Công dụng chính của 2 loài này thường dùng để đan lát hàng thủ công mỹ nghệ (Duong, 2015).

Trong tổng số 25 loài điều tra được có loài Cau lùn (Cau hương) (Areca catechu 'Drawf') có đặc điểm hình thái về đường kính thân, lá, mo, hoa, quả giống như loài Cau ăn trầu (Areca catechu L.) chỉ khác về tốc độ sinh trưởng và chiều dài lóng (Cau ăn trầu phát triển nhanh lóng dài 4 - 10 $\mathrm{cm}$, Cau lùn tốc độ sinh trưởng chậm các đốt dày sít vào nhau) (Pham, 2003) nên chỉ được thống kê thành 1 loài. Có 2 loài mang những hình thái với tên thương mại và ứng dụng trong các kiểu phối kết khác nhau là: Cau hawai (Chamaedorea elegans Mart.) và Kè đỏ (Saribus rotundifolius 

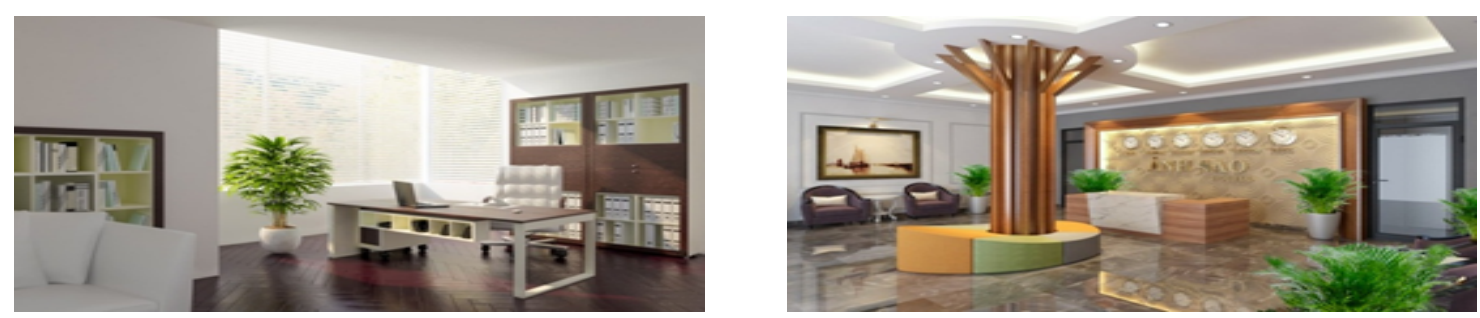

Cây họ Cau dừa trồng chậu trang trí nội thất
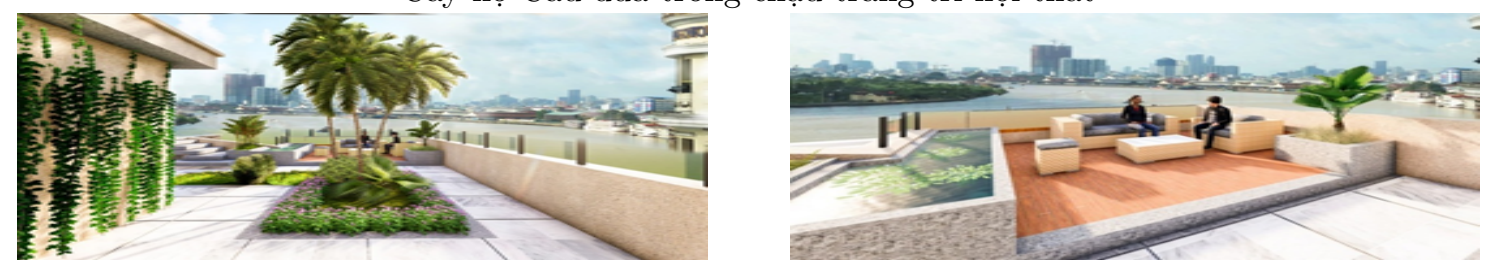

Cây họ Cau dừa trồng bồn trang trí sân thượng
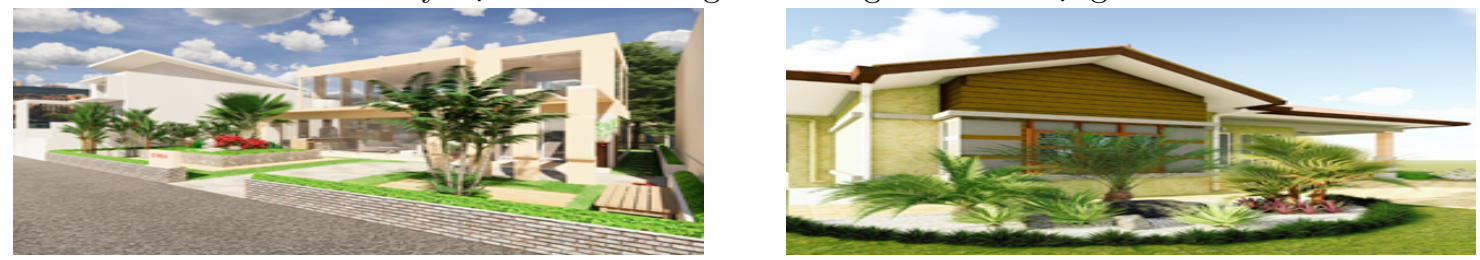

Cây họ Cau dừa trong thiết kế cảnh quan biệt thự, nhà phố
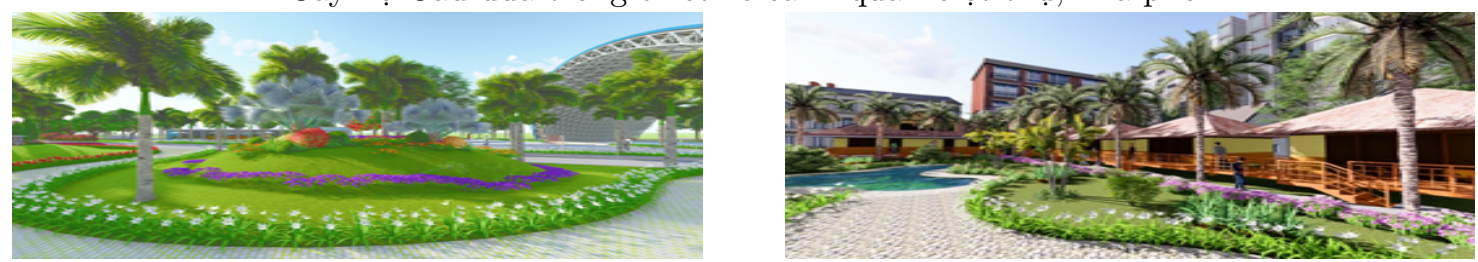

Cây họ Cau dừa trong thiết kế cảnh quan công viên, vườn hoa
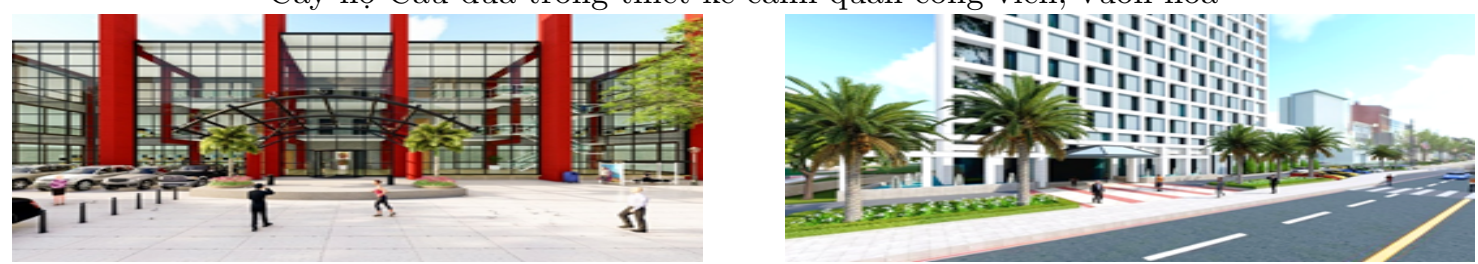

Cây họ Cau dừa trong thiết kế cảnh quan trung tâm thương mại
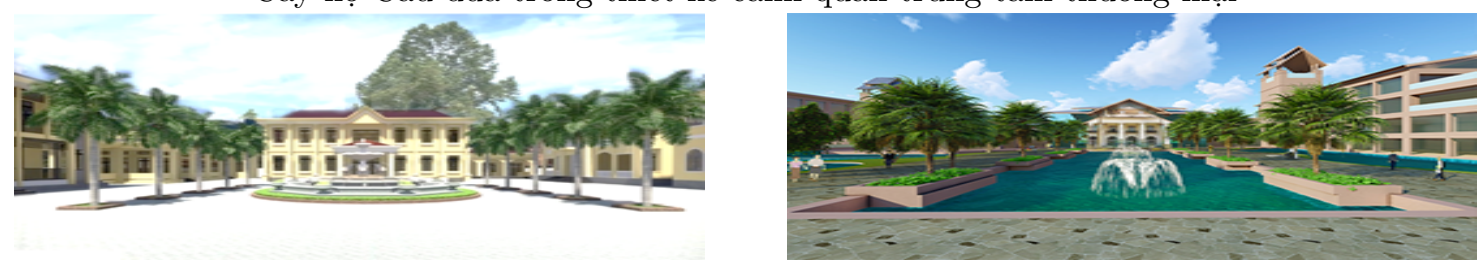

Cây họ Cau dừa trong thiết kế cảnh quan cơ quan hành chính
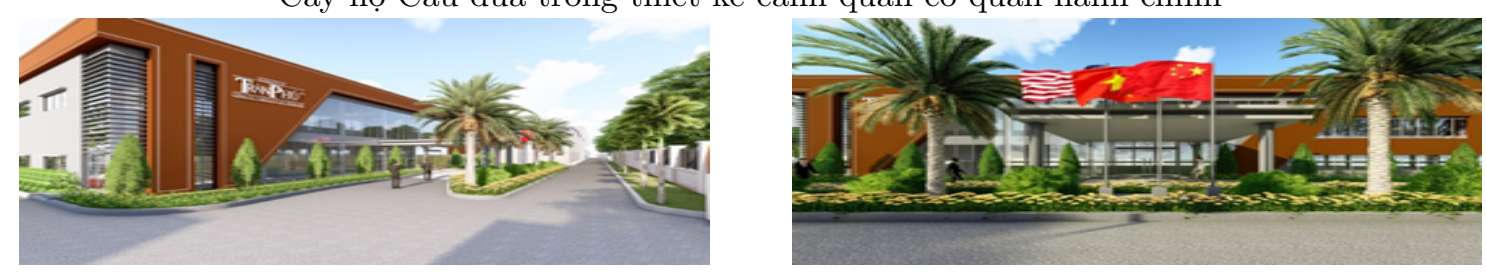

Cây họ Cau dừa trong thiết kế cảnh quan công ty, nhà máy

Hình 1. Ứng dụng cây họ Cau dừa vào một số công trình cảnh quan tiêu biểu. 
(Lam.) Blume). Cau hawai với quy cách nhỏ 20 - $50 \mathrm{~cm}$ gọi là Cau tiểu trâm thường được trồng trong chậu đặt trên bàn làm việc, kệ sách. Kè đỏ là loài đại mộc có thân mọc đơn độc thẳng tắp thường được trồng theo hàng hay cụm, có khi phối kết thêm kiểng lá bên dưới trong các công trình cảnh quan nhằm tạo điểm nhấn, khi còn nhỏ thường được trồng trong chậu để trang trí nội ngoại thất hay ứng dụng làm tường xanh. Ở một số loài có các tua dài thòng xuống với nguồn gốc khác nhau: có thể là do đầu mút các lá chét kéo dài. Vì vậy, tua không phải là đặc điểm đặc trưng của một loài nào đó (Duong, 2015).

\section{2. Ứng dụng cây họ Cau dừa vào một số công trình cảnh quan tiêu biểu}

Cây họ Cau dừa với đặc điểm như thân mọc thẳng, lá tập trung phần ngọn nên khả năng thông gió tự nhiên cao, có tác dụng tạo điểm nhấn cho công trình. Lá đơn có bẹ bọc lấy thân, ít rụng lá, đa dạng về màu (Bảng 2) rất thuận lợi trong lựa chọn phối kết về màu sắc, thuận lợi cho chăm sóc và bảo dưỡng. Khả năng thích ứng với môi trường hạn chế về không gian, rễ không phá hủy kết cấu công trình kiến trúc.

Cây họ Cau dừa ngày nay với nhiều loài cây bản địa và nhập nội đa dạng về kích thước, màu sắc có thể trồng ở nơi có không gian hẹp như chậu hoặc bồn, cho đến những không gian rộng như công viên, vườn hoa, công ty, nhà máy, xí nghiệp (Hình 1). Tuy nhiên, trong điều kiện biến đổi khí hậu như hiện nay, trên đường phố (vỉa hè và dãy phân cách), việc lạm dụng trồng cây họ Cau dừa là chưa phù hợp vì khả năng tạo bóng mát rất thấp, khuyến nghị trồng những loài cây tạo bóng mát có khả năng điều hòa vi khí hậu.

\section{Kết Luận và Kiến Nghị}

Nghiên cứu đã thống kê và định danh được 25 loài thuộc 22 chi. Khu vực quận 7 có $23 / 25$ loài, quận Gò Vấp có $22 / 25$ loài, quốc lộ 22 có $14 / 25$ loài. Trong đó, cây họ Cau dừa có thân đơn độc có 17 loài, cây có thân mọc cụm thành dạng bụi có 8 loài. Cây có tần số xuất hiện cao nhất là Cau vàng (Dypsis lutescens ( $\mathrm{H}$. Wendl.) Beentje \& $\mathrm{J}$. Dransf.) (39 lần), cây có tần số xuất hiện thấp nhất là Kè kim cương (Copernicia alba Morong) (1 lần). Phân loại cây họ Cau dừa theo kích thước; hình thức trồng; màu sắc thân, lá hoặc bẹ lá. Sử dụng phần mềm Sketch - up, Lumion, Photoshop đề xuất thiết kế ứng dụng vào một số công trình cảnh quan tiêu biểu như công viên, vườn hoa, các công trình nội thất. Với khả năng tạo bóng mát rất thấp của cây họ Cau dừa, nghiên cứu đã chỉ ra những hạn chế và việc lạm dụng trồng trên các công trình hạn chế về quỹ đất như đường phố và dải phân cách. Nghiên cứu cần được tiếp tục mở rộng phạm vi điều tra trên các địa bàn quận huyện khác tại Thành phố Hồ Chí Minh và điều tra ứng dụng của cây họ Cau dừa tại các dạng công trình như: công viên, khuôn viên, khu công nghiệp để so sánh tình hình cây cau dừa đã được gây trồng và kinh doanh tại các vựa kiểng.

\section{Lời Cam Đoan}

Bài báo được sự đồng thuận của tất cả các tác giả đứng tên.

\section{Tài Liệu Tham Khảo (References)}

Ali, A., \& Burkhart Jr, L. (2017). Palms: woody giants of the monocots. Retrieved August 4, 2017, from https://www.podchaser.com/podcasts/arborist-newsaudio-142337/episodes/palms-woody-giants-of-themono-19949803.

Bennett, E. M., Peterson, G. D., \& Gordon, L. J. (2009). Understanding relationships among multiple ecosystem services. Ecology Letters 12(12), 1394-1404.

Broschat, T. K. (2007). Boron deficiency, phenoxy herbicides, stem bending and branching in palms: Is there a connection? Palms 51, 161-163.

Dransfield, J., Uhl, N. W., Asmussen, C. B., Baker, W. J., Harley, M. M., \& Lewis, C. E. (2008). Genera palmarum. The evolution and classification of palms. London, UK: Royal Botanic Gardens, Kew.

Duong, H. T. M, (2015). Composition of species and the taxonomic key of family Arecaceae in Hue City. Journal of Science and Education, University of Education, Hue University 04(35), 70-76.

Elmes, A., Rogan, J., Roman, L. A., Williams, C. A., Ratick, S. J., Nowak, D. J., \& Martin, D. G. (2018). Predictors of mortality for juvenile trees in a residential urban-to-rural cohort in Worcester. MA. Urban Forestry \& Urban Greening 30, 138-151.

Farmer, J. (2013). Trees in paradise: a California history. New York, USA: W. W. Norton and Company.

Hansen, R., \& Pauleit, S. (2014). From multifunctionality to multiple ecosystem services? A conceptual framework for multifunctionality in green infrastructure planning forurban areas. Ambio 43, 516-529.

Hauer, R. J., Miller, R. W., Werner, L., \& Konijnendijk van den Bosh, C. C. (2017). The history of trees in the City. In Ferrini, F., \& Konijnendijk van den Bosh, C. C. (Eds.). The Routledge handbook of urban forestry. Oxfordshire, UK: Routledge. 
Hodel, D. R., Pittenger, D. R., \& Downer, A. J. (2005). Palm root growth and implications for transplanting. Journal of Arboriculture 31(4), 171-181.

Nguyen, D. Q. (2017). Study on Arecaceae in Sao La, Thua Thien Hue conservation area. HUAF Journal of Agricultural Science \& Technology 1(2), 247-255.

Nguyen, T. D. (2009). Building database of green trees ornamental flowers for landscape design (Unpublished master's thesis). Nong Lam University, Ho Chi Minh City, Vietnam.

Peper, P. J., McPherson, E. G., Simpson, J. R., Albers, S. N., \& Xiao, Q. (2010). Central florida community tree guide: benefits, costs, and strategic planting. California, USA: Pacific Southwest Research Station.

Pham, H. H. (2003). An illustrated flora of Vietnam. Ho Chi Minh City, Vietnam: Ho Chi Minh City Youth Publishing House.

RoDa, Y. N. (2011). Investigation of the composition of palms at the Saigon zoo and botanical gardens (Unpublished master's thesis). Nong Lam University, Ho Chi Minh City, Vietnam.
Roman, L. A., Battles, J. J., \& McBride, J. R. (2016). Urban tree mortality: a primer on demographic approaches. Pennsylvania, USA: Northern Research Station.

Tran, H. (1998). Trees and ornamental plants in Saigon Ho Chi Minh City. Ho Chi Minh City, Vietnam: Agricultural Publishing House.

Watson, G. (2002). Comparing formula methods of tree appraisal. Journal of Arboriculture 28(1), 11-18.

Xing, Y., \& Brimblecombe, P. (2019). Trees and parks as "the lungs of cities". Urban Forestry \& Urban Greening 48,126552 .

Zhang, M. J., Chen, B., \& Xu, C. (2020). Cultural tree preference and its influence on tree biodiversity in urban public spaces in Nanjing city, China. Urban Forestry \& Urban Greening 48, 126568. 